\title{
Retrospective study of leptospirosis in humans in the city of Manaus, Amazonas (2018-2019)
}

DOI: $10.53499 /$ sfjeasv1n1-001

Received in: November 1st, 2020

Accepted in: December 30th, 2020

\section{George Jefferson Gomes Maia}

Veterinary Medicine Graduate

Institution: Federal Institute of Education, Science and Technology of the State of Amazonas (IFAM), Campus Manaus Zona Leste (CMZL)

Address: Avenue Cosme Ferreira, nº 8.045, Neighborhood: São José Operário, Manaus/AM

E-mail: eugeorgegomes@gmail.com

\section{Mariana Silva Albuquerque \\ Veterinary Doctor}

Institution: Federal Institute of Education, Science and Technology of the State of Amazonas (IFAM), Campus Manaus Zona Leste (CMZL)

Address: Avenue Cosme Ferreira, nº. 8.045, Neighborhood: São José Operário, Manaus/AM

E-mail: mariana10.albuquerque@gmail.com

\section{Eduardo Lima de Sousa}

Master's in agriculture education for Federal Rural University of Rio de Janeiro

Institution: Federal Institute of Education, Science and Technology of the State of Amazonas (IFAM), Campus Manaus Zona Leste (CMZL)

Address: Avenue Cosme Ferreira, $n^{\circ}$. 8.045, Neighborhood: São José Operário, Manaus/AM

E-mail: eduardo.sousa@ifam.edu.br

\section{Edson Francisco do Espírito Santo}

Ph.D. in Animal Science for State University of São Paulo "Júlio de Mesquita Filho" Institution: Federal Institute of Education, Science and Technology of the State of Amazonas (IFAM), Campus Manaus Zona Leste (CMZL)

Address: Avenue Cosme Ferreira, nº. 8.045, Neighborhood: São José Operário, Manaus/AM E-mail: edson.santo@ifam.edu.br

\begin{abstract}
Leptospirosis is an infectious disease of worldwide distribution, transmitted by a highly pathogenic microaerophilic bacterium known as Leptospira spp., from direct contact with infected rodent urine, or in contaminated water and mud. The objective of this study was to carry out an epidemiological characterization of this disease in the city of Manaus, from January 2018 to December 2019, through access to the Notifications Disease Information System - SINAN database, made available by the Foundation of Amazonas Health Surveillance - FVS / AM, and thus make epidemiological inferences through variables such as sex, age, occupation, risk situation occurred in the 30 days prior to the first symptoms, clinical signs, autochthonous case, characteristic of the probable location of the source of infection, work-related disease, the evolution of the case and determination criteria for the characterization of the disease. As a result, 64 cases were confirmed, school distribution as to the regions of the city of $12.5 \%$ of cases in the North zone, $10.94 \%$ in the South zone, $9.37 \%$ in the West zone, $7.82 \%$ in the East zone, and $59.37 \%$ did not have the area identified. Regarding age, the highest prevalence was identified
\end{abstract}


in those under 50 years of age, representing $75 \%$ of total cases. As for gender, $89.06 \%$ of the cases involved males. Regarding risk hypotheses, contact with water or mud from floods was the main infection factor, with $64.60 \%$ of cases, and the main signs comparable to infected individuals were: fever, myalgia, headache, prostration, vomiting, diarrhea, and jaundice. The results show that leptospirosis is a public health problem in the city of Manaus, mainly due to climatic, sanitary, and social factors, the situation in which those susceptible are inserted. Furthermore, a series of socioeconomic and health deficits are located in this municipality, and thus actions and improvements in local public health must be carried out, thus favoring the control of this disease.

Keywords: epidemiology, infectious diseases, veterinary medicine, rodents, zoonoses.

\section{INTRODUTION}

The urbanization and the verticalization of large urban centers have contributed to the increase in cases of several waterborne diseases, in both humans and domestic animals. According to the Health Ministry. in Brazil, leptospirosis is an endemic disease, however, the rain period became epidemic, because the incidence of cases is mainly related to living conditions and sanitation, aiding the human infection (BRASIL, 2018). Beyond the difficulty of installing and maintaining basic sanitation, the proliferation of rodents, and poor rainwater drainage in large population centers have been the main cause of the increase in this casuistry in the country (PEREIRA, 2014).

According to the Health Ministry, between 1999 and 2005, in Brazil were notified 81.887 suspected cases of the disease, with 22,774 confirmed and 2,574 deaths, presenting an incidence of 1.9 per 100,000 inhabitants in the period, not counting the underreporting (SOUZA et al., 2011). However, between the years 2007 to 2016, the casuistic was 39,263 cases of leptospirosis, presenting an annual average of 3,926 cases, an incidence of 1.02 per 100,000 inhabitants, a number relatively lower than that compared to the beginning of the decade (MELO; PECONICK, 2019).

The State of Amazonas has a territory of $1,559,149 \mathrm{~km}^{2}$, being in this federative unit contains the largest hydrographic basin on the planet, an important factor for the characterization of waterborne diseases, since the characteristics of the respective municipalities are associated with rainfall and the availability of water resources in the region (SOUZA; NASCIMENTO, 2017).

The capital, Manaus, has a sanitary and ecological structure that is very favorable to rodent infestation and the occurrence of leptospirosis, due to the humid tropical climate and the distribution of rainfall during a large period of the year. Additionally, the exodus from the interior of the state to this municipality generates several sanitary problems, such as the construction of irregular houses in places without sanitation and near the igarapés (JESUS et al., 2012). In 2016, were notified 40 cases in the capital, and in the following year, the casuistry was increasing with 64 confirmed cases (OLIVEIRA, 2021).

The leptospirosis transmission occurs by a microaerophilic, spiral-shaped, highly infectious, 
pathogenic bacterium belonging to the genus Leptospira spp. (SIMÕES et al., 2016). The main reservoirs are rodents and dogs, and sewer rats (Rattus novergicus) are able to eliminate the spirochetes through their urine without showing any clinical signs (ANDRADE et al., 2018).

The men, terminal and, accidental host of the disease, becomes infected by meeting the urine of infected animals, either directly or indirectly, through contact with contaminated water, mud, or soil. Penetration of the microorganism occurs through injured skin, intact skin when immersed in water for a long time, or through damaged skin (BRASIL, 2014; SIMÕES et al., 2016).

Pathogenic leptospires are capable of producing biofilms, on average 20 days after contact with the environment, which facilitates the contamination of the environment and survival of the microorganism, due to resistance in aquatic environments (MELO; PECONICK, 2019).

The disease presents itself in an evolutionary manner, being divided into two phases: precocious and delayed. Among the symptoms of the $1 \mathrm{ST}$ phase can be note fever of 38 to $39^{\circ} \mathrm{C}$, chills, intense headache, anorexia, diarrhea, nausea, vomiting, malaise, and myalgia (more pronounced in the calf region). Although the precocious phase of the disease corresponds to the majority of clinical forms (90\%), the fewest cases are identified, and consequently, notified in this disease phase, due to the difficulty because of the difficulties inherent in clinical diagnosis and laboratory confirmation. In the second moment, in 10 to $15 \%$ of the cases, the disease evolves to the icteric form (moderate or severe) called Weil's disease, characterized by the triad of jaundice, renal failure, and hemorrhages, the most common of which is pulmonary (BRASIL, 2014).

The disease diagnosis can be laboratorial, from the detection of antibodies in the patient's body, Polymerase Chain Reaction (PCR), and the isolation of leptospires in the acute phase of the disease, easily found in blood, urine, and tissues (SOUZA, 2011). The isolation of leptospires allows an accurate diagnosis of the disease, and the identification of the infecting serovar is important to guide actions aimed at the control and prophylaxis of the disease (SIMÕES et al., 2016). The epidemiological history can be used as a diagnostic tool, and parameters such as the existence of high rodent infestation, the association of suspected cases with seasons with high rainfall, and suggestive clinical manifestations should be considered (SIMÕES et al., 2016). However, the epidemiology and clinical symptoms do not allow the diagnosis, requiring laboratory confirmation (RODRIGUES, 2011).

Given the need for studies to better elucidate this disease, this study aimed to evaluate the epidemiological profile of cases of leptospirosis over a period of two years in the city of Manaus-AM, to characterize this zoonosis in the region. 


\section{MATERIAL E METHODS}

A retrospective study was conducted that contemplated the interval from January 2018 to December 2019, for the quantification of human patients affected by leptospirosis in the city of ManausAM. The information, the data obtained for this research were obtained through access to the database of the Information System for Notifiable Diseases (SINAN), which was made available by the Health Surveillance Foundation of Amazonas (FVS-AM). To obtain the data, we followed the entire institutional process of the FVS, aiming at the speed and legality of the procedures.

For the research, different variables were collected, among them: sex, age, occupation, risk situation in the 30 days prior to the first symptoms (water, flood mud, animal husbandry, water tank, direct contact with rodents, contact with sick humans), clinical signs, autochthonous case, characteristic of the probable site of infection source, work-related disease, case evolution, and confirmation criteria.

In this way, the data was analyzed by means of descriptive statistics in relative percentages within the sample of leptospirosis patients and separated according to the variables, seeking to characterize the profile of this sample in the aforementioned interval.

\section{RESSULT AND DISCUSSION}

Overall, during the study period, were confirmed 64 cases with the following distribution in the Manaus cities: 8 cases $(12,5 \%)$ in the North Zone, 7 (10,94\%) in the South Zone, $6(9,37 \%)$ in the West Zone, $5(7,82 \%)$ in the East Zone and $38(59,37 \%)$ did not have an infection district notified.

In relation to age, 48 patients $(75 \%) 48$ patients $(75 \%)$ were under the age of 50 years; the remainder, in other words, 16 individuals (25\%), were in the age range of 50 years and over. The average age was 37 years, ranging from 13 to 69 years. As for sex, the prevalence was higher in males, totaling 57 cases, representing $89.6 \%$ of them, while female patients totaled only 7 confirmations (10.94\%).

According to Jesus et al. (2012), in a study conducted between 2000 and 2010, in the city of Manaus, the age range was slightly different compared to the present study, ranging from 14 to 44.9 years of age. Regarding gender, the patients most affected by the disease were men, with approximately $85.3 \%$ of the sample, thus maintaining the male gender as more susceptible to the disease. The higher prevalence of leptospirosis in males can be justified by the constant exposure to risky situations, such as garbage collection and sewage maintenance, favoring infection since such occupations are mostly performed by these individuals (SANTOS; COSTA, 2019). As for risk situations up to 30 days before the onset of the clinical picture, five variables were identified, including contact with flood water or mud, animal husbandry, contact with water tanks, direct contact with rodents, and contact with infected humans, as shown in Graph 1. 
Graph 1 - Risk situations involving the 64 confirmed cases of leptospirosis, in the last 30 days before the first symptoms and respective variables, from January 2018 to December 2019, in the municipality of Manaus-

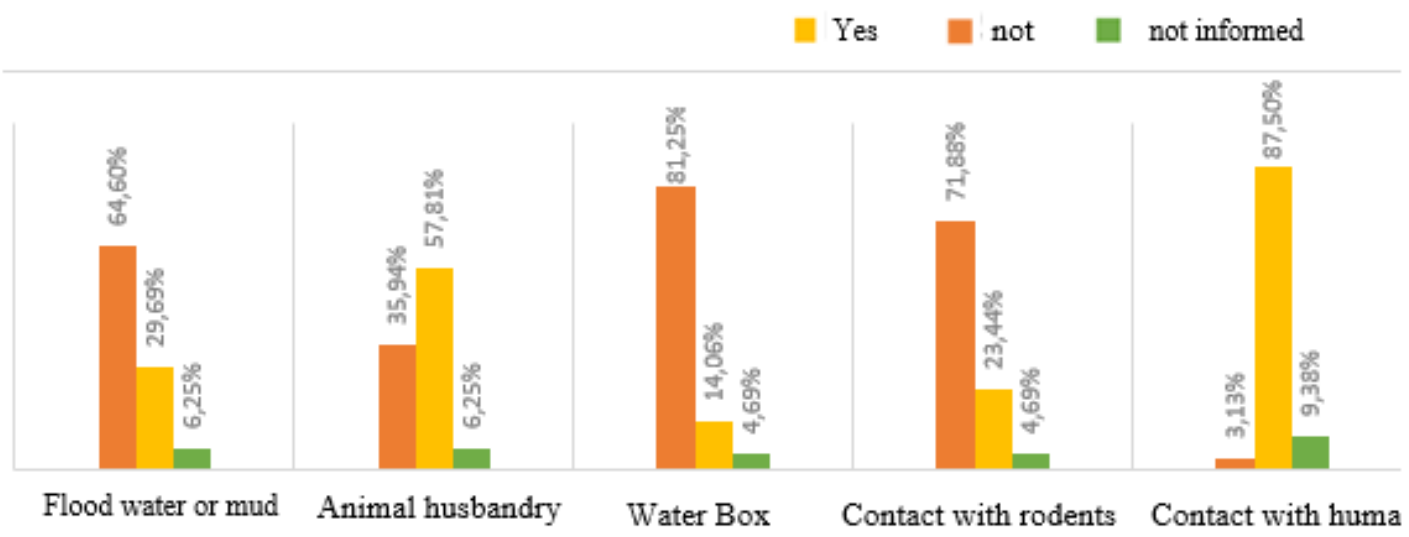

According to Gracie et al. (2021), the leptospirosis rate is higher in municipalities with flooding and recurrent flooding, up to $72 \%$ higher than in places without flooding, taking into account that contact with flood water or mud is among the main risk situations, if not the main one for leptospirosis in the Brazilian territory.

The main clinical signs were fever, myalgia, headache, prostration, vomiting, diarrhea, jaundice, respiratory alterations, and calf pain. Fever was identified in $100 \%$ of the patients, followed by myalgia in $87.50 \%$ of the cases, headache in $85.94 \%$, and jaundice in $82.81 \%$ of the confirmations. The main clinical signs are shown in Graph 2.

Although not specific symptoms for the diagnosis of leptospirosis, signs such as choluria, otalgia, disorientation, hemoptysis, cough, chills, epigastralgia, hematemesis, hematuria, rhabdomyolysis, arthralgia, epistaxis, abdominal pain, hypertension, chest pain, lymphadenomegaly, petechiae, anorexia, arthritis, fatigue, and dysuria were also reported. According to Baracho et al. (2015), generally, the cases of leptospirosis begin with the symptomatology of a flu-like condition, with nonspecific symptoms, such as headache, fever, malaise, and muscle pain in the first phase of the disease.

Graph 2 - Quantitative of clinical signs in percentage (\%) found in the confirmed cases of leptospirosis, from January 2018 to December 2019, in the municipality of Manaus-AM.

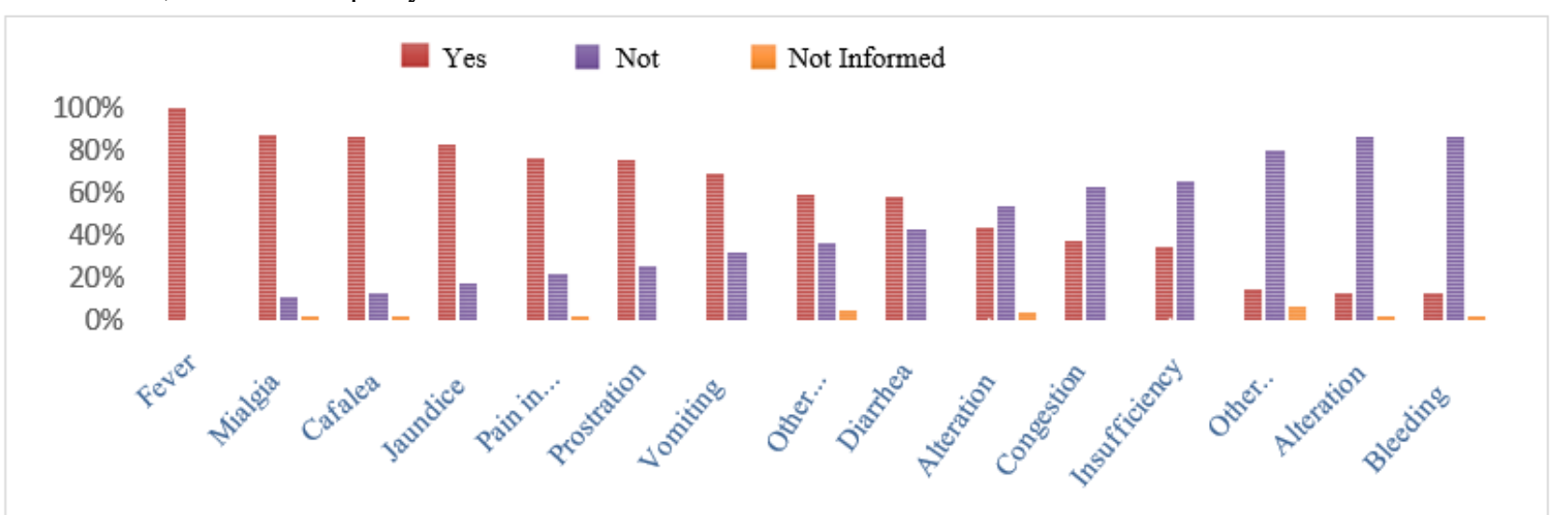


Regarding the form of infection, 60 cases $(93.75 \%)$ were autochthonous, 1 case $(1.56 \%)$ was allochthonous, and 3 cases (4.69\%) were not identified. Regarding the characteristic of the probable infection site, 55 cases $(85.94 \%)$ were reported in urban areas, 1 case $(1.56 \%)$ in rural areas, no cases in peri-urban areas, and 8 cases $(12.5 \%)$ had no locality reported. Regarding the environment of infection, the household was predominant, with 29 cases $(45.31 \%)$ followed by the workplace, accounting for 16 cases $(25 \%)$. The environments of infection reported are shown in Chart1.

Chart 1: Classification of the infection environment for leptospirosis, in Manaus, between January 2018 and December 2019.

\begin{tabular}{ccc}
\hline Infection Setting & Number of cases (n) & Percentage $(\%)$ \\
\hline Home & 29 & 45,31 \\
Work & 16 & 25,00 \\
Leisure & 2 & 3,13 \\
Other & 4 & 6,25 \\
Not Informed & 13 & 20,31 \\
\hline Total & 64 & 100,00
\end{tabular}

According to Rocha (2019), in a study conducted in Santa Catarina, between the years 2012 and 2017, 2312 cases were identified, and the home environment was considered the place with the highest prevalence of infection, totaling $41.35 \%$ of the cases, followed by the work environment, with $27.12 \%$ of them, a situation that highlights a certain pattern in relation to the findings in the municipality of Manaus.

Regarding the patient's occupational risk, the disease was related in 18 cases (28.13\%). In 33 cases $(51.56 \%)$ this risk was denied, and in another 13 cases $(20.31 \%)$ the occupational risk was not informed. According to Silva et al. (2010), at the end of the twentieth century, leptospirosis was a disease linked to unhealthy work, with a high incidence among workers in the sanitation system, considering that failures in the garbage collection system are a key factor for the number of leptospirosis cases (SILVA et al., 2010), a situation that continues to occur today, added to other health problems.

Most patients showed cures in the clinical picture, ten died due to complications of the disease, and two did not have the evolution of the case reported, as shown in Chart 2.

Chart 2: Evolution of leptospirosis in confirmed cases between January 2018 and December 2019, in the city of Manaus-AM.

\begin{tabular}{ccc}
\hline Death & Number of cases (n) & Percentage (\%) \\
\hline Cure & 52 & 81,25 \\
Death & 10 & 15,63 \\
Not Informed & 2 & 3,13 \\
\hline Total & 64 & 100,00 \\
\hline
\end{tabular}

As for the criteria for confirmation of the disease, the majority was laboratory-based, representing 52 cases $(81.25 \%)$, and the rest, 12 cases $(18.75 \%)$, were clinical-epidemiological. Although the clinical- 
epidemiological criteria are used to diagnose leptospirosis, complementary tests such as serology, molecular and bacteriological tests should always be used. The most common techniques to be used according to Souza (2011) are microscopic serum agglutination (MAT), ELISA-IgM, and isolation of the bacterium.

\section{FINALS CONSDERATIONS}

It is concluded that leptospirosis is a disease that predominates in tropical climates, and in the city of Manaus, it becomes epidemic, eventually between December and June, due to the recurring floods in the region. The occurrence of the disease is mainly due to socioeconomic factors, sanitary conditions, and the presence or absence of adequate basic sanitation in which susceptible individuals fit.

One of the main forms of transmission is through contact with the urine of infected rodents and presents a rapid evolution, however, without proper treatment, the prognosis is considered unfavorable to the health of the patient.

From the data collected for this study, it is possible to identify several failures in items related to local public health and sanitation deficiencies that can easily be improved, such as adequate water drainage, and especially the control of synanthropic rodents. It is hoped that this work can contribute to the implementation of public actions in the region and that further studies on this problem can be carried out.

\section{ACKNOWLEDGMENTS}

We thank the Amazonas State Research Support Foundation (FAPEAM) for making the research possible through financial support, the FVS-AM, for making the database available, and everyone involved in the course of the activities. 


\section{REFERENCES}

Andrade, T. S., Mendes, M. O., Praseres, B. S., Sena, E. O., Santos, F. R., Freitas, J. L. (2018). Clinical aspects of dogs with leptospirosis in the veterinary medicine hospital. Brazilian Journal of Animal and Environmental Research, 1 (1), 91-98.

Baracho, J. M., Lima, N. B., Costa, A. P. R. (2017). Incidence of human Leptospirosis cases in Pernambuco: An analysis of 2015 epidemiological data. Biological and Health Sciences Unit, 3 (2), 1932.

Brazil. Ministry of Health. Secretariat of Health Surveillance. (2018). Leptospirosis: Epidemiological situation in Brazil from 2007 to 2016. Epidemiological bulletin. Available at: $<$ https://antigo.saude.gov.br/images/pdf/2018/outubro/25/2018-033-Leptospirose-situa----o-epidemiol-gica-do-Brasil-no-per--odo-de-2007-a-2016-publica--ao.pdf>. Acess in: 6 Jun. 2021.

Brazil. Ministry of Health. Secretariat of Health Surveillance. Department of Surveillance of Transmissible Diseases. (2014). Leptospirosis: diagnosis and clinical management. Available at: <https://bvsms.saude.gov.br/bvs/publicacoes/leptospirose-diagnostico-manejo-clinico2.pdf>. Acess in: 16 de maio de 2021.

Gracie, R., Xavier, D. R., Medronho, R. (2021). Flooding and leptospirosis in Brazilian municipalities from 2003 to 2013: using data mining techniques. Cadernos de Saúde Pública, 37 (5), 1-15.

Jesus, M. S., Silva, L. A., Lima, K. M. S., Fernandes, O. C. C. (2012). Distribution of leptospirosis cases in the municipality of Manaus, Amazonas state, Brazil, 2000-2010. Revista da Sociedade Brasileira de Medicina Tropical, 45 (6), 713-716.

Melo, T. F., Peconick, A. P. (2019). The characteristics of Leptospira spp.: a literature review. Scire Salutis, 9 (3), 1-7.

Oliveira, L. L. P., Oliveira, W. G. P., Ribeiro, R. S. P. (2021). Epidemiological profile of Leptospirosis cases in the Northern region from 2016 to 2019. Jnt- Facit business and technology journal, 1 (24), 169181.

Pereira, E. R. Leptospirosis. 30f. Monograph (Bachelor in Pharmacy). Faculty of education and environment, Ariquemes, 2014.

Rocha, M. F. (2019). Epidemiological profile of leptospirosis in Santa Catarina: A descriptive analysis of the last five years. Journal of Veterinary Science and Public Health, 6 (2), 342-358.

Santos, T. D. A., Costa, A. D. P. (2019). Retrospective analysis on leptospirosis in the metropolitan region of Rio de Janeiro from 2015 to 2019. PubVet, 15 (6), 1-8.

Silva, D. X., Barcellos, C., Bacuri, R. (2010) Preliminary diagnosis of vulnerability and predictions of climate change effects on public health in the municipality of Manaus. Fiocruz-Observatory of climate and health. Available at <https://climaesaude.icict.fiocruz.br/\%C3\%A1rea-de-vigilancia/manaus-1>. Accessed on: 25 abr. 2021.

Simões, L. S., Sasahara, T. H. C., Favaron, P. O., Miglino, M. A. (2016). Leptospirosis - Review. PubVet, 10 (2), 138-146. 
Souza, R. F., Nascimento, S. L. (2017). Diseases and Agraves in the context of large gradual floods in the state of Amazonas - Brazil. Brazilian Journal of Medical and Health Geography, 13 (26), 139-147.

Souza, V. M. M., Arsky, M. L. N. S., Castro, A. P. B., Araújo, W. N. (2011). Potential years of life lost and hospital costs of leptospirosis in Brazil. Revista de Saúde Pública, 45 (6) 1001-1008.

Souza, V. R. Leptospirosis: clinical, epidemiologic and laboratory aspects. 33f. Monografia (Graduation in Clinical Analysis and Laboratory Management). Faculdade de Ciências da Saúde da Universidade Vale do Rio Doce, 2011. 